\title{
Thermodynamics of Solute Distributions between Solid and Liquid Phases in Iron-base Ternary Alloys*
}

\author{
By Zen-ichiro MORIT $A^{* *}$ and Toshihiro TANAKA***
}

\section{Synopsis}

The equilibrium distribution coefficients $k_{\circ}$ for some solutes in iron-base ternary alloys have been experimentally investigated. The mechanisms of these solute distributions between solid and liquid phases were also discussed on the basis of thermodynamics.

The experimental results show that $k_{\circ}$ of $\mathrm{Ni}$ increases and $k_{\circ}$ of $\mathrm{V}$ decreases with the increasing carbon content, and the distributions of $\mathrm{G}$ in $\mathrm{Fe}-\mathrm{C}-\mathrm{Ni}$ and $\mathrm{Fe}-\mathrm{C}-\mathrm{V}$ alloys differ little from those in $\mathrm{Fe}-\mathrm{C}$ binary alloys. This effect of carbon on $k_{\circ} s$ of $\mathrm{Ni}$ and $\mathrm{V}$ could be thermodynamically explained by using the interaction parameter, the activity coefficient and so on.

And also, the effects of various alloying elements on the equilibrium distributions of nitrogen and hydrogen were discussed thermodynamically.

\section{Introduction}

The equilibrium distribution coefficients of solute elements in iron alloys are known to play an important role in relation to the segregation during the solidification of steel. Generally, the liquidus in most important systems has been considerably well established by the thermal analysis. However, informations on the solidus and the distribution coefficients especially in multi-component systems are sparse and generally unreliable. The equilibrium distribution coefficients of some elements in multi-component systems are thought to be different from those in binary systems since some interactions among solutes are expected to exist in multi-component systems, but a comprehensive theory concerning this problem has not yet been developed.

Recently, some investigators ${ }^{1-5)}$ measured the equilibrium distribution coefficients of solute elements in various kinds of iron alloys and calculated them by using thermodynamical data. However, in their works, mainly, they studied if the experimental results were valid or not in comparison with the calculated values, and did not discuss the mechanism of the equilibrium distribution of solute and the effect of solute interaction on it.

The purpose of this work is to obtain the equilibrium distribution coefficients for $\mathrm{C}, \mathrm{Ni}$ and $\mathrm{V}$ in $\mathrm{Fe}-\mathrm{C}-\mathrm{Ni}$ (up to $4 \mathrm{wt} \% \mathrm{C}$ and $1 \mathrm{wt} \% \mathrm{Ni}$ ) and $\mathrm{Fe}-\mathrm{C}_{-}-$ $\mathrm{V}$ (up to $4 \mathrm{wt} \% \mathrm{C}$ and $3 \mathrm{wt} \% \mathrm{~V}$ ) alloys and to discuss the mechanisms of these solute distributions between solid and liquid phases. In these systems, there are few data for the equilibrium distribution coefficients of the solutes, especially in a wide temperature range. Since the thermodynamic interaction between $\mathrm{Ni}$ and $\mathrm{G}$ in iron alloy is known to be opposite to that between
$\mathrm{V}$ and $\mathrm{C}$, it is also interesting from a thermodynamic standpoint to make clear the mechanisms of distributions of $\mathrm{Ni}$ and $\mathrm{V}$. Moreover, based on the results on these systems, the factors which control the solute distributions between solid and liquid phases in iron base binary alloys and iron-carbon base ternary ones are discussed thermodynamically.

Also, the distributions of nitrogen and hydrogen between solid and liquid phases in iron-base alloys are discussed thermodynamically.

\section{Experimental}

\section{Apparatus for Quenched Specimens}

The apparatus for preparing quenched specimens is shown in Fig. 1. A sample weighing about $5 \mathrm{~g}$ was placed into an alumina crucible in purified argon gas atmosphere. After the sample melted down, it was cooled to a fixed temperature between $1180^{\circ} \mathrm{C}$ and $1420^{\circ} \mathrm{C}$, at which austenite and liquid phases coexisted, and held at that temperature for a given time. When the equilibrium was achieved, by withdrawing the stopper, the sample fell through the hole at the bottom of crucible and was quenched in oil or $10 \%$ $\mathrm{KOH}$ aqua, to make the specimen including two

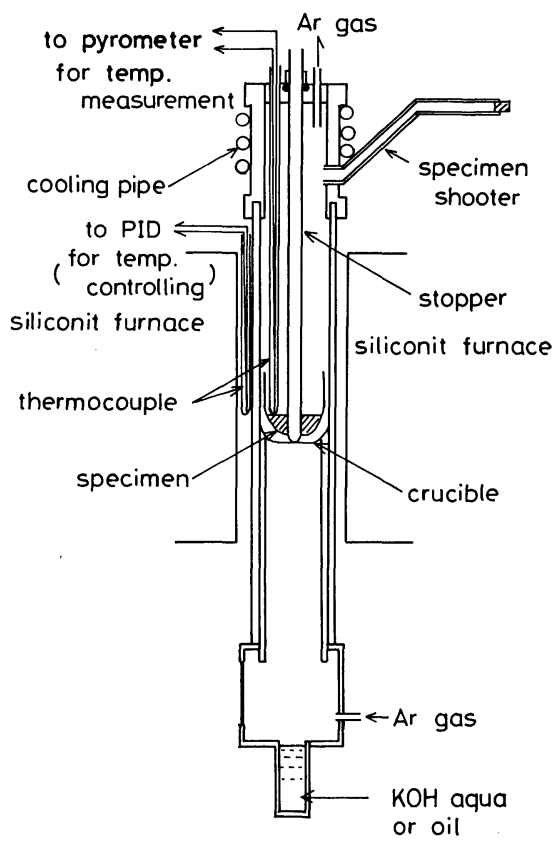

Fig. 1. Apparatus for quenching specimens.

\footnotetext{
* Presented to the 104th ISIJ Meeting, September 1982, S1021, at Hokkaido University in Sapporo and Japan-U.S. Seminar on Advances in Science of Iron- and Steelmaking, May 1983, in Kyoto. Manuscript received March 4, 1983. (C) 1983 ISIJ

** Department of Metallurgical Engineering, Faculty of Engineering, Osaka University, Yamadaoka, Suita 565.

*** Graduate School, Osaka University, Yamadaoka, Suita 565.
} 
phases of liquid and solid before quenching.

As the vertical tube furnace had a hot zone of $30 \mathrm{~mm}$ over which the temperature was constant within $\pm 2 \mathrm{~K}$ and the height of the sample was shorter than $10 \mathrm{~mm}$, it is reasonable to expect that the temperature distribution in the sample was uniform. The sample was often stirred when it was held at a given temperature so that the solids could distribute uniformly in the sample.

\section{Sample and Holding Temperature}

The compositions of the samples used and their equilibrium holding temperatures are listed in Table 1. These samples were prepared in a high frequency induction furnace from electrolytic iron, pure graphite, nickel and vanadium.

The equilibrium temperature was fixed at about $20{ }^{\circ} \mathrm{C}$ lower than the liquidus temperature to make the ratio of solid to liquid in the specimen as small as possible.

\section{Equilibration Time}

To determine the time required for the establishment of the complete equilibrium between the two phases, a series of experiments were carried out on the $\mathrm{Fe}-\mathrm{C}-\mathrm{V}$ alloys, in which the specimens were quenched after different holding times at the same temperature. The results of the analysis of $\mathrm{V}$ from the central regions of the solid phases are given in Fig. 2. This figure shows clearly that the equilibrium has been achieved after $3 \mathrm{hr}$. Consequently, the holding time was determined to be 3 to $4 \mathrm{hr}$.

\section{Metallographic Structure of Quenched Specimens and the Measurement of Concentration Distribution by EPMA}

All the specimens were spherical, and the solid phases were distributed uniformly in each specimen. Photograph 1 shows the microstructures of the quenched specimens, where circulars and the rest are the solid and liquid phases, respectively, which had coexisted before quenching.

All the specimens quenched were prepared for metallographic examinations by polishing and etching in $10 \%$ Nital. Then, the parts of solid and liquid to be microanalysed were marked out with microhardness impressions, and then repolished to remove the etching.

Electron probe microanalysis was carried out at an accelerating voltage of $20 \mathrm{kV}$ by scanning the focussed beam at $50 \mu \mathrm{m} / \mathrm{min}$ over the region which included both solid and liquid. Since, particularly, the structure of the part of the liquid phase in the specimen was not uniform as that of the solid phases, in the part of the liquid phase a focussed beam was moved over the distance corresponding to 2 or 3 times of the diameter of the part of the solid phase, and then the concentrations of the solutes at the liquid region of each specimen were averaged.

The actual compositions were obtained from the calibration curve which was previously established with the chemically analysed specimens of $\mathrm{Fe}-\mathrm{C}-\mathrm{V}$ and $\mathrm{Fe}-\mathrm{C}-\mathrm{Ni}$ alloys, shown in Fig. 3. The chemical
Table 1. Chemical composition and equilibration temperature for $\mathrm{Fe}-\mathrm{C}-\mathrm{Ni}$ and $\mathrm{Fe}-\mathrm{C}-\mathrm{V}$ alloys.

\begin{tabular}{ccc|ccc} 
wt\% $\mathrm{C}$ & wt $\% \mathrm{~V}$ & wt $\% \mathrm{Ni}$ & \multicolumn{3}{|c}{ Holding temperature $[\mathrm{K}]$} \\
\hline 2.57 & 1.03 & & 1543 & 1548 & \\
3.50 & 1.06 & & 1468 & 1476 & \\
2.30 & 0.44 & & 1628 & 1643 & 1653 \\
3.34 & 0.44 & & 1536 & 1546 & \\
2.45 & 2.96 & & 1622 & 1632 & \\
3.37 & 2.80 & & 1543 & & \\
1.62 & & 0.39 & 1673 & 1683 & \\
2.77 & & 0.48 & 1573 & 1593 & \\
3.28 & & 0.59 & 1526 & 1556 & \\
2.71 & & 1.03 & 1605 & 1608 & 1613 \\
3.84 & & 0.93 & 1473 & 1483 & 1490 \\
\hline
\end{tabular}

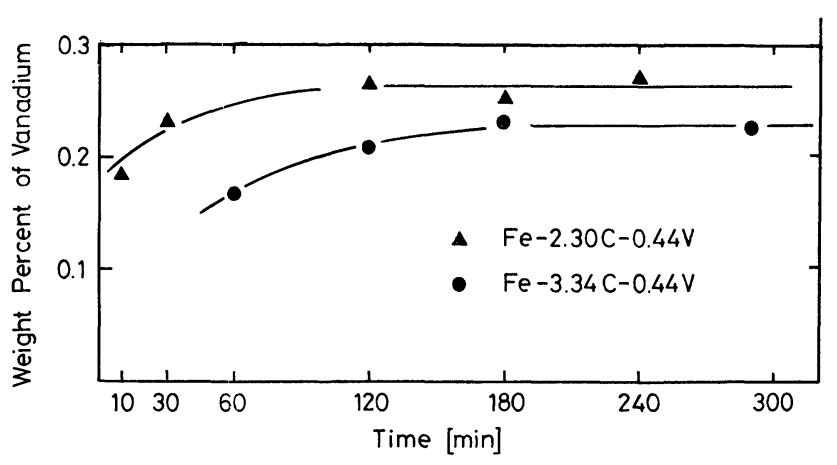

Fig. 2. Vanadium concentration in austenite of $\mathrm{Fe}-\mathrm{C}-\mathrm{V}$ alloys with equilibration time.

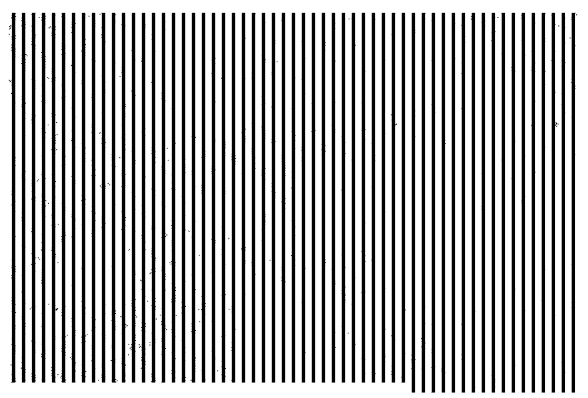

$\mathrm{Fe}-3.84 \mathrm{C}-0.93 \mathrm{Ni}$

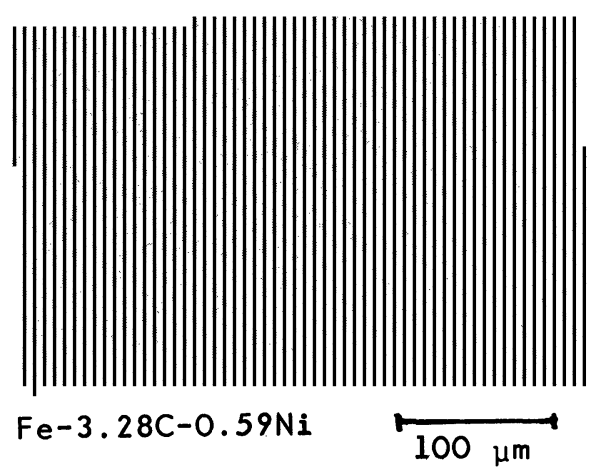

Photo. 1. Microstructures of quenched specimens.

compositions of these samples used are listed in Table 2. Some examples of the concentration distribution measured by EPMA are given in Fig. 4. 

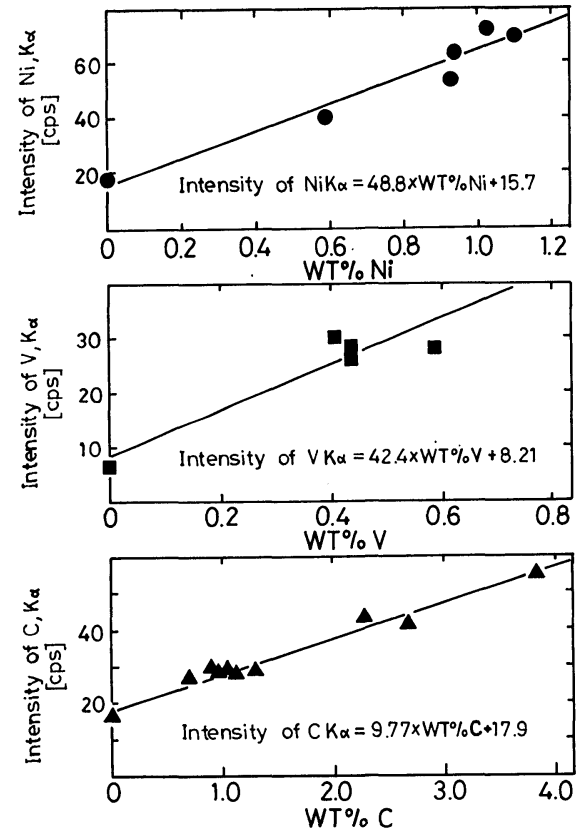

Fig. 3. Calibration curves for $\mathrm{Ni}, \mathrm{V}$ and $\mathrm{G}$ in electron probe microanalysis.

Table 2. Chemical composition for standard specimens.

\begin{tabular}{|c|c|c|}
\hline wt $\% \mathrm{C}$ & wt $\% \mathrm{~V}$ & wt $\% \mathrm{Ni}$ \\
\hline 0.00 & 0.00 & 0.00 (pure iron) \\
\hline 0.71 & 0.44 & \\
\hline 0.97 & 0.59 & \\
\hline 1.04 & 0.41 & \\
\hline 2.30 & 0.44 & \\
\hline 3.34 & 0.44 & \\
\hline 0.92 & & 1.10 \\
\hline 1.14 & & 0.59 \\
\hline 1.31 & & 0.94 \\
\hline 2.71 & & 1.03 \\
\hline 3.84 & & 0.93 \\
\hline
\end{tabular}

\section{Experimental Results}

Figure 5 shows the experimental results on a plot of the carbon concentration in both the austenite and liquid phases in $\mathrm{Fe}-\mathrm{C}-\mathrm{Ni}$ and $\mathrm{Fe}-\mathrm{C}-\mathrm{V}$ systems together with the liquidus and solidus in Fe-C binary system. It is obvious that the distribution of $\mathrm{C}$ between the solid and liquid phases in $\mathrm{Fe}-\mathrm{C}-\mathrm{Ni}$ and $\mathrm{Fe}-\mathrm{C}-\mathrm{V}$ alloys with $1 \sim 3 \mathrm{wt} \% \mathrm{Ni}$ and $\mathrm{V}$ differs little from that in $\mathrm{Fe}-\mathrm{C}$ binary system.

The variation of the equilibrium distribution coefficient of $\mathrm{Ni}, k_{\circ}^{\mathrm{N} 1}$, in $\mathrm{Fe}-\mathrm{C}-\mathrm{Ni}$ system and that of $\mathrm{V}$, $k_{\circ}^{\mathrm{v}}$, in $\mathrm{Fe}-\mathrm{C}-\mathrm{V}$ system are given as a function of the carbon concentration of liquidus, respectively, in Figs. 6 and 7. In these figures, the calculated values of $k_{\circ}^{\mathrm{N} 1}$ and $k_{\circ}^{\mathrm{v}}$ using thermodynamic data are also shown. This calculation will be discussed in detail at the later section. It can be seen from Figs. 6 and 7 that $k_{\circ}^{\mathrm{N}}$ increases in $\mathrm{Fe}-\mathrm{C}-\mathrm{Ni}$ system and $k_{\mathrm{o}}^{\mathrm{V}}$ decreases in $\mathrm{Fe}-\mathrm{C}-\mathrm{V}$ systems with the increasing carbon content. The effects of $\mathrm{Ni}$ and $\mathrm{V}$ contents on $k_{\mathrm{o}}^{\mathrm{N1}}$ and $k_{\mathrm{o}}^{\mathrm{V}}$ in Figs. 6 and 7 are seemingly negligible. Also the

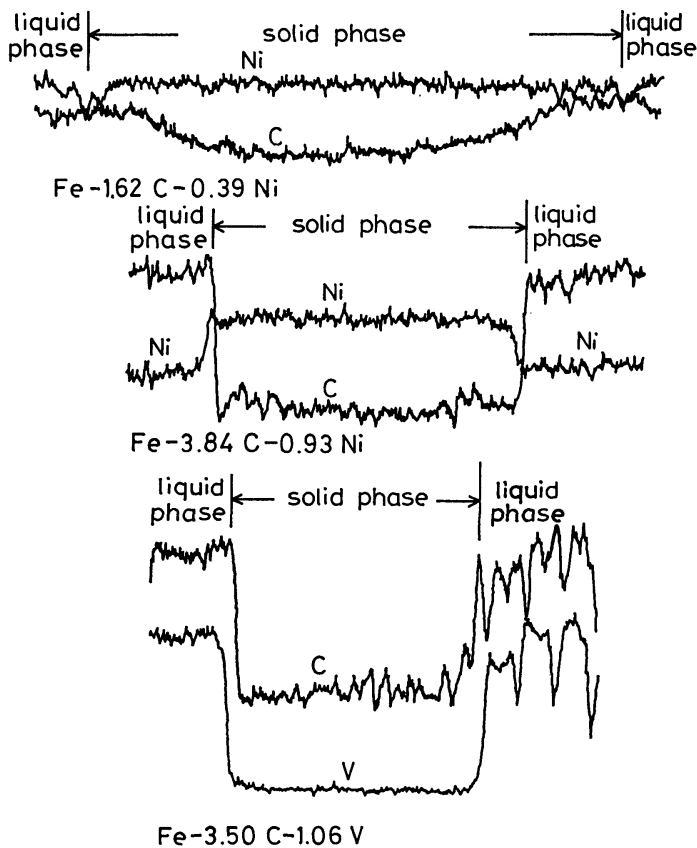

Fig. 4. Carbon, nickel and vanadium distributions in quenched specimens.

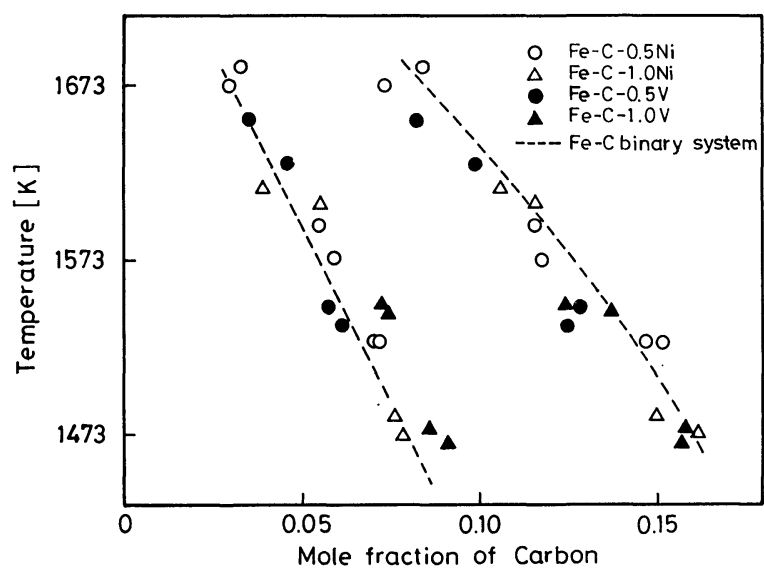

Fig. 5. Carbon distribution between austenite and liquid phases in $\mathrm{Fe}-\mathrm{C}-\mathrm{Ni}$ and $\mathrm{Fe}-\mathrm{C}-\mathrm{V}$ systems.

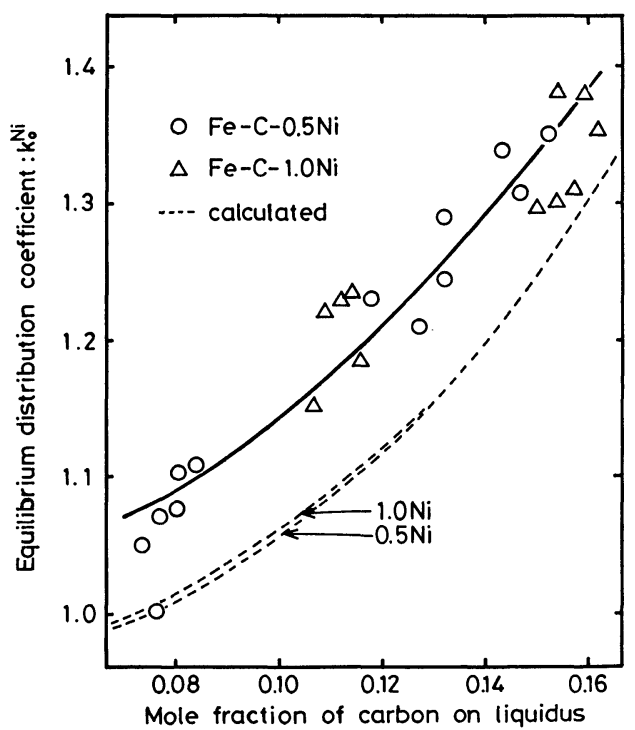

Fig. 6. Change of $k_{\circ}$ of $\mathrm{Ni}$ in $\mathrm{Fe}-\mathrm{C}-\mathrm{Ni}$ alloys with carbon concentration on liquidus. 


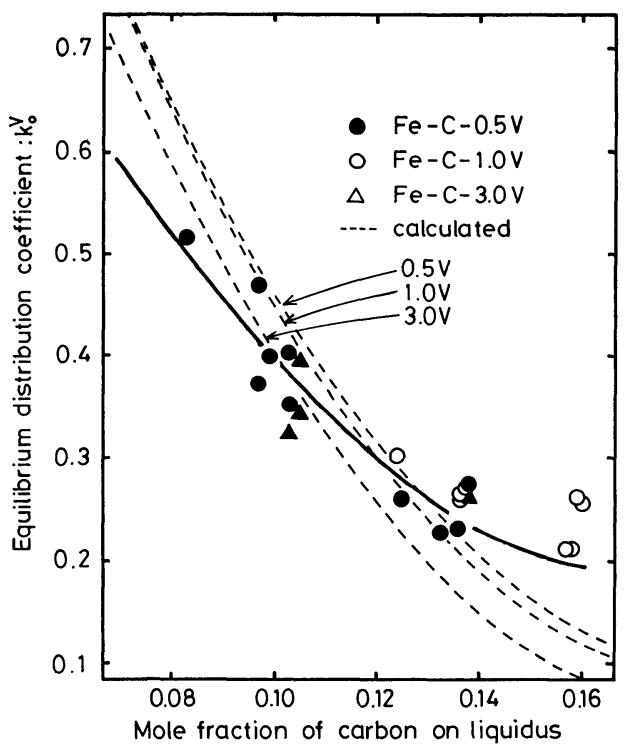

Fig. 7. Change of $k_{\circ}$ of $\mathrm{V}$ in $\mathrm{Fe}-\mathrm{C}-\mathrm{V}$ alloys with carbon concentration on liquidus.

experimental results are thought to be in reasonable agreement with the calculated ones.

\section{Discussion}

Studies on the effect of interaction among solutes on the equilibrium distribution coefficients in multicomponent iron alloys have not been experimentally established, and neither theoretically. Recently, the calculation techniques for equilibrium phase diagrams by a computer have been developed and some phase diagrams for multicomponent systems have been obtained through the use of these techniques. But the relations between the interactions among solutes and the distribution of the solutes have not been made clear. In this section, the equilibrium distribution coefficient is discussed thermodynamically in order to clarify the controlling factor of solute distribution between solid and liquid phases in iron alloys.

Also, the effects of some alloying elements on the nitrogen and hydrogen distributions are discussed thermodynamically.

1. Thermodynamic Treatment of Equilibrium Distribution Coefficient $k_{\circ}^{\mathrm{x}}$ and the Periodicity of $k_{\circ}^{\mathrm{x}}$ of Solute $X$ in Iron Alloys

Equilibrium between liquid and solid phases in an iron-rich alloy is represented by Eqs. (1) to (3)

$$
\begin{aligned}
& \mu_{\mathrm{X}}^{l}=\dot{\mu}_{\mathrm{X}}^{l}+R T \ln \left(\gamma_{\mathrm{X}}^{l} \cdot \mathcal{N}_{\mathrm{X}}^{l}\right) \\
& \mu_{\mathrm{X}}^{s}=\dot{\mu}_{\mathrm{X}}^{s}+R T \ln \left(\gamma_{\mathrm{X}}^{s} \cdot \mathcal{N}_{\mathrm{X}}^{s}\right) \\
& \mu_{\mathrm{X}}^{l}=\mu_{\mathrm{X}}^{s} \quad \ldots \ldots \ldots \ldots \ldots \ldots \ldots \ldots \ldots \ldots \ldots \ldots \ldots \ldots
\end{aligned}
$$

where, $\mu_{\mathrm{X}}$ : the chemical potential of $\mathrm{X}$

$\dot{\mu}_{\mathrm{X}}$ : the chemical potential of $\mathrm{X}$ in standard state

$\mathcal{N}_{\mathrm{X}}:$ the mole fraction of $\mathrm{X}$

$\gamma_{X}:$ activity coefficient of $X$

$R:$ the gas constant

$T:$ the absolute temperature

the superscripts $l$ and $s$ : liquid and solid state.
From Eq. (3) of the equilibrium condition, the equilibrium distribution coefficient of $\mathrm{X}, k_{\mathrm{o}}^{\mathrm{x}}$, is derived as follows:

$$
\begin{aligned}
k_{\mathrm{o}}^{\mathrm{x}} & =\mathcal{N}_{\mathrm{X}}^{s} / \mathcal{N}_{\mathrm{X}}^{l} \\
& =\exp \left\{\left(\dot{\mu}_{\mathrm{X}}^{l}-\dot{\mu}_{\mathrm{X}}^{s}\right) / R T\right\} \cdot \exp \left(\ln \gamma_{\mathrm{X}}^{l}-\ln \gamma_{\mathrm{x}}^{s}\right) \ldots \ldots
\end{aligned}
$$

Generally, when the equilibrium distribution coefficient is read from the phase diagram, the value obtained from the tangents of the solidus and the liquidus at their cross point, that is to say, the point $\mathcal{N}_{\mathbf{X}}^{l}, \mathcal{N}_{\mathrm{X}}^{s} \rightarrow 0$ as sketched in Fig. 8, is regarded to be valid near the melting point of iron. Then, as $\mathcal{N}_{\mathrm{X}}^{l}{ }^{\text {or } s} \rightarrow 0$, Eq. (4) can be simplified to

$$
\begin{aligned}
k_{\mathrm{o} N_{\mathbf{X}} \rightarrow 0}^{\mathrm{X}} & =\left(\mathcal{N}_{\mathbf{X}}^{s} / \mathcal{N}_{\mathbf{X}}^{l}\right)_{N_{\mathbf{X}} \rightarrow 0} \\
& =\exp \left\{\left(\dot{\mu}_{\mathbf{X}}^{l}-\dot{\mu}_{\mathbf{X}}^{s}\right) / R T\right\} \cdot \exp \left(\ln \dot{\gamma}_{\mathbf{X}}^{l}-\ln \dot{\gamma}_{\mathbf{X}}^{s}\right)
\end{aligned}
$$

where, $\dot{\gamma}_{\mathrm{X}}$ : the activity coefficient of element $\mathrm{X}$ at the infinite dilution.

In Bragg-Williams approximation, the activity coefficient of element $\mathrm{X}$ in a binary system of $\mathrm{Fe}$-substitutional element $\mathrm{X}$ is given by ${ }^{6}$ )

$$
\ln \gamma_{\mathrm{X}}=\left\{W_{\mathrm{Fe}-\mathrm{x}} \cdot\left(1-\mathcal{N}_{\mathrm{X}}\right)^{2}\right\} / R T
$$

and in a system of $\mathrm{Fe}$-interstitial element $\mathrm{X}$ binary one

$$
\ln \gamma_{\mathrm{x}}=\left(W_{\mathrm{Fe}-\mathrm{X}}+2 \mathcal{N}_{\mathrm{x}} \chi_{\mathrm{x}}\right) / R T
$$

where, $W_{\mathrm{Fe}-\mathrm{x}}$ : the interchange energy between $\mathrm{Fe}$ and $\mathrm{X}$

$\chi_{\mathrm{X}}$ : the binding energy of solute $\mathrm{X}$.

As $\mathcal{N}_{\mathrm{X}} \rightarrow 0$ in Eqs. (6) and (7), both these equations are expressed as

$$
\left(\ln \gamma_{\mathrm{X}}\right)_{N_{\mathrm{X}^{\rightarrow}} 0}=\ln \dot{\gamma}_{\mathrm{X}}=W_{\mathrm{Fe}-\mathrm{x}} / R T
$$

Substituting Eq. (8) into Eq. (5) gives

$$
\begin{aligned}
& k_{\circ}^{\mathrm{X}}{ }_{N_{\mathbf{X}} \rightarrow 0}=\left(\mathcal{N}_{\mathbf{X}}^{s} / \mathcal{N}_{\mathbf{X}}^{l}\right)_{N_{\mathbf{X}} \rightarrow 0} \\
& =\exp \left\{\left(\dot{\mu}_{\mathrm{X}}^{l}-\dot{\mu}_{\mathrm{X}}^{s}\right) / R T\right\} \cdot \exp \left\{\left(W_{\mathrm{Fe}-\mathrm{X}}^{l}\right.\right. \\
& \left.\left.-W_{\mathrm{Fe}-\mathrm{x}}^{s}\right) / R T\right\}
\end{aligned}
$$

It is obvious from Eq. (9) that the equilibrium distribution coefficient of solute element $\mathrm{X}$ at the infinite dilution consists of the free energy of fusion of element $\mathrm{X}$ and the difference between the interchange energies of $\mathrm{Fe}-\mathrm{X}$ in liquid phase and in solid one. Also these energies are dependent upon only the properties of element $\mathrm{X}$. Then, in order to examine the above results the change of equilibrium distribution coefficient of element $\mathrm{X}$ with its atomic number will be considered.

The equilibrium distribution coefficients of element $\mathrm{X}$ in iron alloys published by other investigators ${ }^{7)}$ are plotted against the atomic number of the element $\mathrm{X}$ in Fig. 9. As exhibited in this figure, the equilibrium distribution coefficients of element $\mathrm{X}$ are thought to change periodically against the atomic number. Then, this periodical change will be discussed through the comparison with the above equation (9).

First of all, the calculated free energy of fusion of each element at the melting point of iron is shown in 


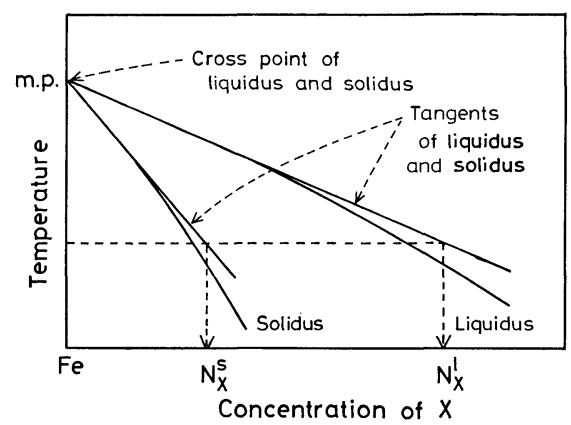

Fig. 8.

Sketch of solidus and liquidus near the melting point of iron.

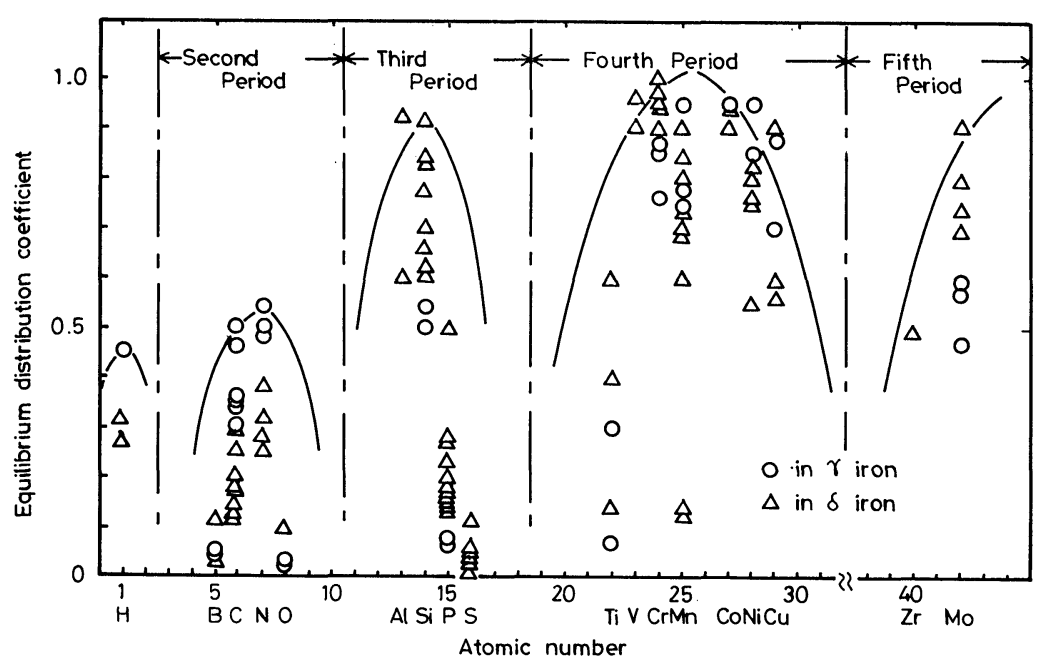

Fig. 9. Change of equilibrium distribution coefficients in iron alloys with atomic number.
Fig. 10(A). It is obvious from this figure that the free energy of fusion changes periodically against the atomic number of the element.

Generally, the interchange energy is considered to be dependent upon both the differences in the atomic size (size factor) and the chemical property (chemical factor). For example, Mott ${ }^{8}$ proposed the following equation as the interchange energy between $\mathrm{A}$ and $\mathrm{B}$ elements.

$$
W_{A-B}=V_{M}\left(\delta_{A}-\delta_{B}\right)^{2}-23060 \bar{n}\left(\chi_{A}-\chi_{B}\right)^{2}
$$

where, $V_{M}:$ the atomic volume of the alloy

$$
\begin{aligned}
& \delta: \text { the solubility parameter } \\
& \chi: \text { the electronegativity } \\
& \bar{n}: \text { the number of } A-B \text { bonding. }
\end{aligned}
$$

Therefore, the differences of the atomic radius as the size factor and the electronegativity as the chemical factor between $\mathrm{Fe}$ and a solute element are taken into account and plotted against the atomic number of the element, respectively, in Figs. 10(B) and (C). As exhibited in these figures, both the size factor and the chemical one also change periodically against the atomic number, and this fact suggests the existence of a periodicity on interchange energy.

Thus, from the foregoing Eq. (9) it is considered reasonable that the equilibrium distribution coeffcients of the solute element in iron base alloys change periodically against the atomic number of the element.

Consequently, the free energy of fusion of element $\mathrm{X}$ and the difference of interchange energy between $\mathrm{Fe}$ and element $\mathrm{X}$ are considered to be the fundamental factors controlling the equilibrium distribution of the element $\mathrm{X}$ in iron alloys.

\section{The Equilibrium Distribution Coefficient of the Third Element in $\mathrm{Fe}-\mathrm{C}$ Base Ternary Alloys}

The foregoing experimental results of this work showed that $k_{\circ}^{\mathrm{N} 1}$ in $\mathrm{Fe}-\mathrm{C}-\mathrm{Ni}$ system increased and $k_{\circ}^{\mathrm{V}}$ in $\mathrm{Fe}-\mathrm{C}-\mathrm{V}$ system decreased with the increasing carbon content. In this section let us examine these results thermodynamically.

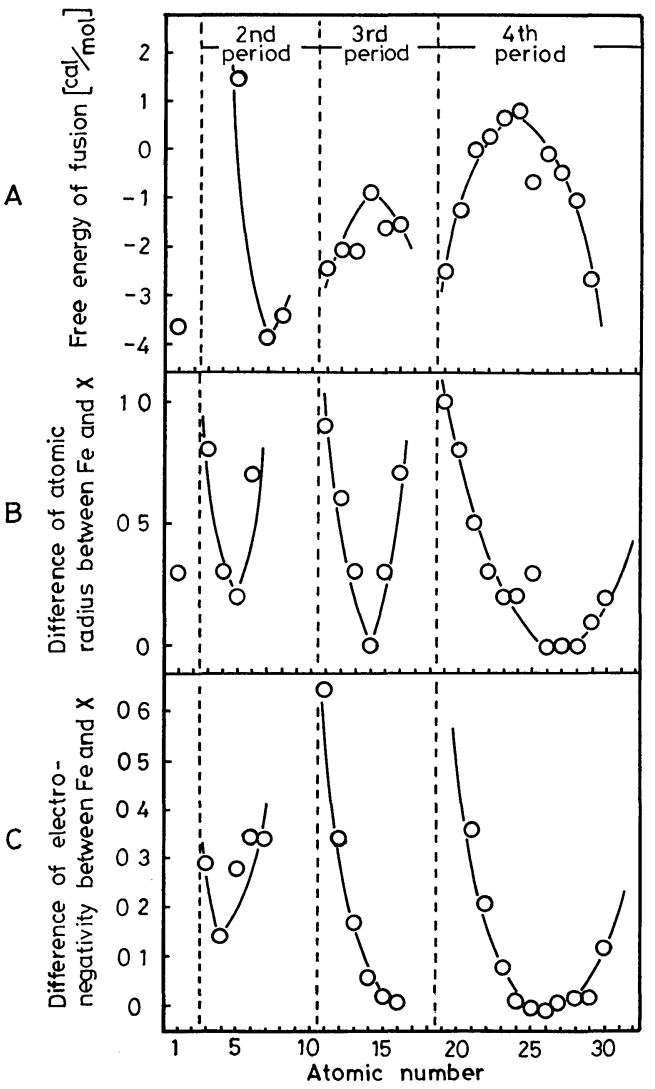

Fig. 10. Periodicity for free energy of fusion of element $\mathrm{X}$ and difference of atomic radius and electronegativity between $\mathrm{Fe}$ and $\mathrm{X}$.

Equation (4) can also be applied for the equilibrium distribution coefficient of element $\mathrm{X}$ in $\mathrm{Fe}-\mathrm{C}-\mathrm{X}$ ternary system. In this case, the effect of carbon must be included in the activity coefficient $\gamma_{\mathrm{x}}$ of element $\mathrm{X}$ in Eq. (4). Then, to consider the effect of $\mathrm{C}$, the activity coefficient of element $\mathrm{X}$ is expressed in terms of the interaction parameter $\varepsilon$ as follows:

$$
\ln \gamma_{\mathrm{x}}=\ln \dot{\gamma}_{\mathrm{x}}+\varepsilon_{\mathrm{x}}^{\mathrm{x}} \mathcal{N}_{\mathrm{x}}+\varepsilon_{\mathrm{X}}^{\mathrm{d}} \mathcal{N}_{\mathrm{C}}
$$

where, $\varepsilon_{\mathrm{x}}^{\mathrm{x}}$ : the self-interaction parameter of element $\mathrm{X}$ 
$\varepsilon_{\mathrm{X}}^{\mathrm{C}}:$ the interaction parameter of $\mathrm{C}$ on $\mathrm{X}$. By substituting Eq. (10) and the relations $k_{\circ}^{\mathrm{x}}=\mathcal{N}_{\mathbb{x}}^{s} /$ $\mathcal{N}_{\mathrm{x}}^{l}$ and $k_{\mathrm{o}}^{\mathrm{C}}=\mathcal{N}_{\mathrm{C}}^{s} / \mathcal{N}_{\mathrm{c}}^{l}$ into Eq. (4), the equilibrium distribution coefficient of element $\mathrm{X}$ in $\mathrm{Fe}-\mathrm{C}-\mathrm{X}$ ternary system is represented by

$$
\begin{aligned}
\ln k_{\mathrm{o}}^{\mathrm{x}}= & \left(\dot{\mu}_{\mathrm{X}}^{l}-\dot{\mu}_{\mathrm{X}}^{s}\right) / R T+\ln \left(\dot{\gamma}_{\mathrm{X}}^{l} / \dot{\gamma}_{\mathrm{X}}^{s}\right) \\
& +\left(\varepsilon_{\mathrm{X}}^{\mathrm{X}}, l-\varepsilon_{\mathrm{X}}^{\mathrm{X}}, s k_{\mathrm{o}}^{\mathrm{X}}\right) \cdot \mathcal{N}_{\mathrm{X}}^{l} \\
& +\left(\varepsilon_{\mathrm{X}}^{\mathrm{C}, l}-\varepsilon_{\mathrm{X}}^{\mathrm{C}}, s k_{\mathrm{o}}^{\mathrm{C}}\right) \cdot \mathcal{N}_{\mathrm{C}}^{l} \quad \ldots \ldots \ldots
\end{aligned}
$$

Here, the first and second terms show the fundamental factor controlling $k_{\circ}^{\mathrm{x}}$, the third and the fourth terms denote the concentration dependences of $\mathrm{X}$ and $\mathrm{C}$, respectively, on $k_{\circ}^{\mathrm{x}}$. Thus $k_{\circ}^{\mathrm{x}}$ can be calculated by substituting thermodynamic data into Eq. (11). The calculated $k_{\circ}^{\mathrm{Ni}}$ and $k_{\circ}^{\mathrm{v}}$ are shown in Figs. 6 and 7 with the experimental ones. The thermodynamic data used in the above calculation are given in Table $3 .{ }^{9-18)}$

Now, let us call attention to the fourth term in the right-hand side of Eq. (11). Mori and Ichise ${ }^{20)}$ proposed that there exists a linear relation of $\varepsilon_{\mathrm{N}}^{\mathrm{x}}$ in solid and liquid phases, $\varepsilon_{\mathrm{N}}^{\mathrm{X}}, s=m \cdot \varepsilon_{\mathrm{N}}^{\mathrm{X}}, l$, in iron-nitrogen-X systems. The value $m$, which is not strictly equal to unity, is considered to be related to the difference of the structure between solid and liquid phases. Then, we applied this treatment for $\mathrm{Fe}-\mathrm{C}-\mathrm{X}$ systems. The relations of some elements $\mathrm{X}$ between $\varepsilon_{\mathbf{X}}^{\mathrm{C}, l}$ in liquid phase $^{9)}$ and $\varepsilon_{\mathrm{X}}^{\mathrm{C}, s}$ in solid one $\mathrm{9}^{9-12,14,19)}$ are shown in Fig. 11. In this figure, it is obvious that a linear relation holds approximately between $\varepsilon_{\mathrm{X}}^{\mathrm{C}, l}$ and $\varepsilon_{\mathrm{X}}^{\mathrm{C}}, s$. This relation obtained by the least square method is given as

$$
\varepsilon_{\mathrm{X}}^{\mathrm{C}, s}=0.925 \varepsilon_{\mathrm{X}}^{\mathrm{c}, l}
$$

Substituting Eq. (12) into the fourth term in the right-hand side of Eq. (11) yields

$$
\left(\varepsilon_{\mathrm{X}}^{\mathrm{C}, l}-\varepsilon_{\mathrm{X}}^{\mathrm{C}, s} k_{\circ}^{\mathrm{C}}\right) \cdot \mathcal{N}_{\mathrm{C}}^{l}=\varepsilon_{\mathrm{X}}^{\mathrm{C}, l}\left(1-0.925 k_{\circ}^{\mathrm{C}}\right) \cdot \mathcal{N}_{\mathrm{C}}^{l}
$$

As the equilibrium distribution coefficient of $\mathrm{C}, k_{\circ}^{\mathrm{c}}$, takes the value smaller than unity, in the above equation $^{13)}$

$$
\left(1-0.925 k_{\circ}^{\mathrm{c}}\right)>0
$$

It is obvious from Eqs. (11) and (13) that since $\varepsilon_{\mathrm{X}}^{\mathrm{C}, l}$ is positive for the element $\mathrm{X}$ with the repulsive effect against $\mathrm{C}$, the value of the fourth term in the right-

\begin{tabular}{|c|c|c|c|c|c|}
\hline & & Austenite & Ref. & Liquid & Ref. \\
\hline \multirow{4}{*}{ Nickel } & $\ln \dot{\gamma}_{\mathrm{Ni}}$ & $-0.386\left(1300^{\circ} \mathrm{C}\right),-\frac{607 * 2}{T}^{*}$ & 10) & $-0.416\left(1600^{\circ} \mathrm{C}\right),-\frac{773^{* 2}}{T}$ & 9) \\
\hline & $\varepsilon_{\mathrm{Ni}}^{\mathrm{Ni}}$ & $\frac{1200}{T}$ & $* 1$ & $\frac{1560}{T}$ & $* 1$ \\
\hline & $\varepsilon_{\mathrm{C}}^{\mathrm{Ni}}$ & $\frac{4640}{T}+0.65$ & 11) & $2.85\left(1600^{\circ} \mathrm{C}\right),{\frac{5340^{* 2}}{T}}^{* 2}$ & 9) \\
\hline & \multicolumn{5}{|c|}{$\dot{\mu}_{\mathrm{Ni}}^{l}-\dot{\mu}_{\mathrm{Ni}}^{\gamma}=21.6 \cdot T+0.90 \times 10^{-3} \cdot T^{2}-3.2 \cdot T \cdot \ln T+1257$} \\
\hline \multirow{4}{*}{ Vanadium } & $\ln \dot{\gamma} v$ & $-3.10\left(1000^{\circ} \mathrm{C}, \alpha\right.$ phase $),-\frac{3950 * 2, * 3}{T}$ & 18) & $-1.80\left(1600^{\circ} \mathrm{C}\right),-\frac{3360}{T}^{* 2}$ & 13) \\
\hline & $\varepsilon_{\mathrm{V}}^{\mathrm{V}}$ & $\frac{7900}{T}$ & $* 1$ & $3.23\left(1600^{\circ} \mathrm{C}\right), \frac{6050 * 2}{T}^{* 2}$ & 9) \\
\hline & $\varepsilon_{\mathrm{C}}^{\mathrm{V}}$ & $-18.4\left(1000^{\circ} \mathrm{C}\right),-\frac{23400^{* 2}}{T}$ & 12) & $-16.1\left(1600^{\circ} \mathrm{C}\right),-\frac{30100^{* 2}}{T}$ & 9) \\
\hline & \multicolumn{5}{|c|}{$\dot{\mu}_{\mathrm{v}}^{l}-\dot{\mu}_{\mathrm{V}}^{\alpha}=48.6 \cdot T+1.29 \times 10^{-3} \cdot T^{2}-0.1 \times 10^{5} \cdot T^{-1}-6.45 \cdot T \cdot \ln T-3935$} \\
\hline \multirow{2}{*}{ Carbon } & $\ln \dot{\gamma}_{\mathrm{C}}$ & $\frac{8680}{T}+2.72 \ln T-24.3$ & 14) & $\frac{2720}{T}-2.00$ & 15) \\
\hline & $\varepsilon_{\mathrm{C}}^{\mathrm{C}}$ & $\frac{8980}{T}+3.00$ & 14) & $\frac{7830}{T}+3.66$ & 15) \\
\hline
\end{tabular}
hand side of Eq. (11) becomes positive and the $k_{\circ}^{\mathrm{x}}$

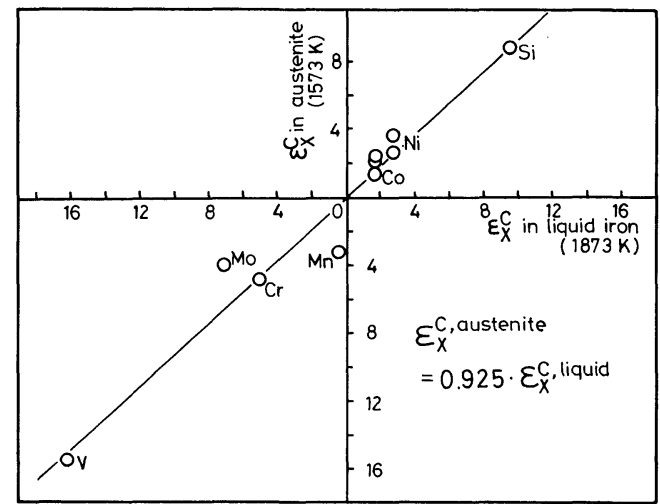

Fig. 11. Relation between $\varepsilon_{\mathrm{X}}^{\mathrm{C}, l}$ in liquid and $\varepsilon_{\mathrm{X}}^{\mathrm{C}, s}$ in austenite.

Table 3. Thermodynamic data for calculating $k_{\mathrm{o}}^{\mathrm{Ni}}$ and $k_{\mathrm{o}}^{\mathrm{v}}$.

*1 Estimated from the equation $\varepsilon_{\mathrm{x}}^{\mathrm{x}}=-2 \ln \dot{\gamma} \mathrm{x}$.

*2 Temperature dependence is estimated in this work.

*3 The value of the term $\left\{\left(\dot{\mu}_{\mathrm{V}}^{l}-\dot{\mu}_{\mathrm{V}}^{\gamma}\right)+R T \ln \dot{\gamma}_{\mathrm{V}}^{l} / \dot{\gamma}_{\mathrm{V}}^{\gamma}\right\}$ in liq. $-\gamma$ phase equilibrium is calculated from the equation:

$\left\{\left(\dot{\mu}_{\mathrm{v}}^{l}-\dot{\mu}_{\mathrm{v}}^{\gamma}\right)+R T \cdot \ln \dot{\gamma}_{\mathrm{v}}^{l} / \dot{\gamma}_{\mathrm{v}}^{\gamma}\right\}=\left\{\left(\dot{\mu}_{\mathrm{v}}^{l}-\dot{\mu}_{\mathrm{v}}^{\alpha}\right)+R T \cdot \ln \dot{\gamma}_{\mathrm{v}}^{l} / \dot{\gamma}_{\mathrm{v}}^{\alpha}\right\}+\left\{\left(\dot{\mu}_{\mathrm{v}}^{\alpha}-\dot{\mu}_{\mathrm{v}}^{\gamma}\right)+R T \cdot \ln \dot{\gamma}_{\mathrm{v}}^{\alpha} / \dot{\gamma}_{\mathrm{v}}^{\gamma}\right\}$

in liq. $-\gamma$ equilibrium in liq. $\alpha$ equilibrium in $\alpha-\gamma$ equilibrium

where the last term is equal to $\left(R T \ln k_{\mathrm{o}}^{\mathrm{V}}(\alpha-\gamma)=R T \ln \mathcal{N}_{\mathrm{V}}^{\gamma} / \mathcal{N}_{\mathrm{V}}^{\alpha}\right.$ in Fe-V binary system) $\mathcal{N}_{\mathrm{V} \rightarrow 0}=-0.577 \cdot T$ (Ref. 17)). 
increases with the increasing $\mathrm{C}$ content. On the other hand, since $\varepsilon_{\mathrm{X}}^{\mathrm{G}, l}$ is negative for the element $\mathrm{X}$ with the attractive effect against $\mathrm{C}$, the value of the fourth term of Eq. (11) becomes negative and the $k_{\mathrm{o}}^{\mathrm{x}}$ decreases with the increasing $\mathrm{C}$ content.

Figure 12 shows a plot of the present experimental results, $k_{\circ}^{\mathrm{N} 1}$ and $k_{\circ}^{\mathrm{V}}$ as a function of the $\mathrm{G}$ content, together with $k_{\circ}^{\mathrm{x}}$ for some kinds of elements published by other workers. ${ }^{1-3,21-26)}$ As illustrated in this figure, in $\mathrm{Fe}-\mathrm{C}-\mathrm{Ni}, \mathrm{Fe}-\mathrm{C}-\mathrm{Si}$ and $\mathrm{Fe}-\mathrm{C}-\mathrm{Co}$ systems, $k_{\circ}^{\mathrm{N} 1}, k_{\circ}^{\mathrm{si}}$ and $k_{\circ}^{\mathrm{Co}}$ increase with the increasing $\mathrm{C}$ content because these elements denote the repulsive effect against $\mathrm{C}$. While $\mathrm{V}, \mathrm{Mn}$ and $\mathrm{Cr}$ indicate the attractive effect against $\mathrm{C}$ in $\mathrm{Fe}-\mathrm{C}$ base alloy systems, so $k_{\circ}^{\mathrm{v}}, k_{\circ}^{\mathrm{Mn}}$ and $k_{\circ}^{\mathrm{Cr}}$ decrease with the increasing $\mathrm{C}$ content. Thus, the present experimental results could be understood as described above.

Besides, it has been reported that $\varepsilon_{\mathrm{C}}^{\mathrm{x}}$ in liquid iron alloys changes periodically against the atomic number of element X. ${ }^{27}$ Upon combining Eqs. (11) and (13), we presume that in $\mathrm{Fe}-\mathrm{C}$ base alloys the effects of $\mathrm{C}-\mathrm{X}$ interactions on $k_{\mathrm{o}}^{\mathrm{x}}$ change periodically against the atomic number of element $\mathrm{X}$.

Consequently, the fourth term in the right-hand side of Eq. (11) can be expected as an important factor controlling the variation of $k_{\circ}^{\mathrm{x}}$ as a function of the $\mathrm{C}$ content in $\mathrm{Fe}-\mathrm{C}-\mathrm{X}$ alloys.

Moreover, in order to investigate the fourth term of Eq. (11) the influence of $\mathrm{C}$ on $k_{\circ}^{\mathrm{x}}$ is intended to be estimated quantitatively in terms of free energy. Namely, multiplying each term in Eq. (11) by $R T$ where $R$ is the gas constant and $T$ is the absolute temperature, we derive

$$
\begin{aligned}
& R T \ln k_{\mathrm{o}}^{\mathrm{x}}=\left(\dot{\mu}_{\mathrm{x}}^{l}-\dot{\mu}_{\mathrm{X}}^{s}\right)+R T \ln \left(\dot{\gamma}_{\mathrm{x}}^{\mathrm{l}} / \dot{\gamma}_{\mathrm{x}}^{\mathrm{s}}\right) \\
& +R T\left(\varepsilon_{\mathbf{X}}^{\mathbf{X}}, l-\varepsilon_{\mathbf{X}}^{\mathbb{X}}, s \cdot k_{\circ}^{\mathrm{X}}\right) \cdot \mathcal{N}_{\mathbf{X}}^{l} \\
& +R T\left(\varepsilon_{\mathrm{X}}^{\mathrm{G}}, t-\varepsilon_{\mathrm{X}}^{\mathrm{G}}, \cdot k_{\mathrm{o}}^{\mathrm{o}}\right) \cdot \mathcal{N}_{\mathrm{C}}^{l}
\end{aligned}
$$

We define the physical meaning of each term in this equation as follows:

The left-hand term: the energy to let $\mathrm{X}$ distribute by the ratio $k_{0}^{x}$

The first and second terms of the right-hand side: the energy controlling $k_{\circ}^{\mathrm{x}}$ fundamentally

The third term: the energy depending on the $\mathrm{X}$ content

The fourth term: the energy depending on the interaction of $\mathrm{C}$ on $\mathrm{X}$.

Figure 13 depicts the variation of the calculated energies of each term in Eq. (15) as a function of temperature in $\mathrm{Fe}-\mathrm{C}-\mathrm{Ni}$ and $\mathrm{Fe}-\mathrm{C}-\mathrm{V}$ systems, respectively. It is clear from this figure that the energy depending on the interaction of $\mathrm{C}$ on $\mathrm{Ni}$ and $\mathrm{V}$ is the most dominant factor among these energies related to $R T$ $\ln k_{\circ}^{x}$.

\section{Equilibrium Distributions on Nitrogen and Hydrogen} between Solid and Liquid Phases in Iron Base Alloys

Informations on solubilities of gaseous elements in iron base alloys are known to play an important role in the development of some qualities of steels. In general the solubilities of nitrogen and hydrogen in

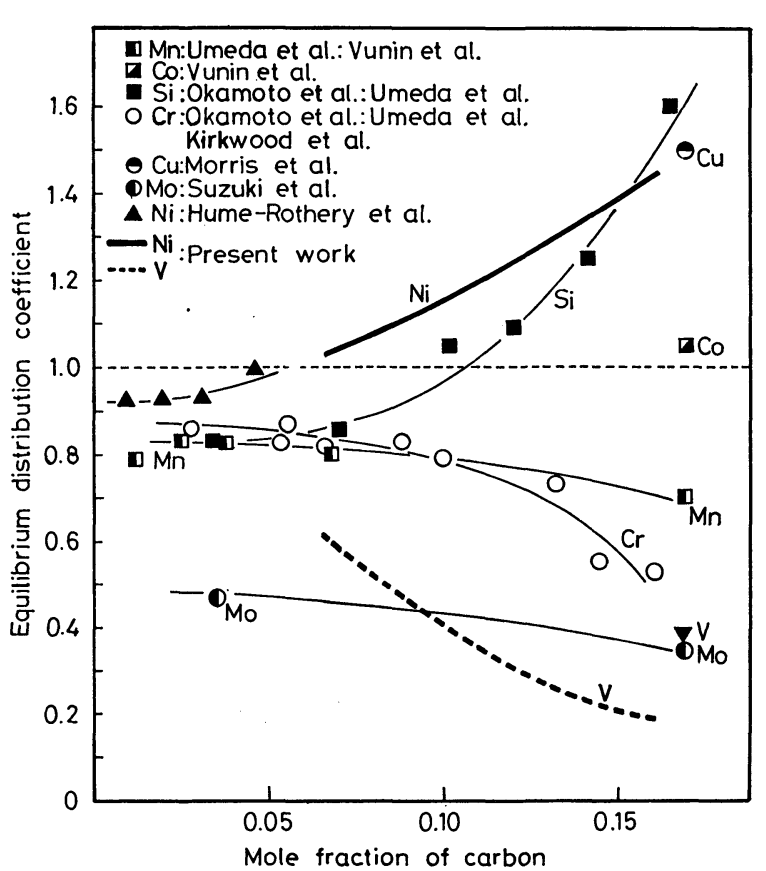

Fig. 12. Change of equilibrium distribution coefficient of some elements with carbon content in iron-carbon base alloys.
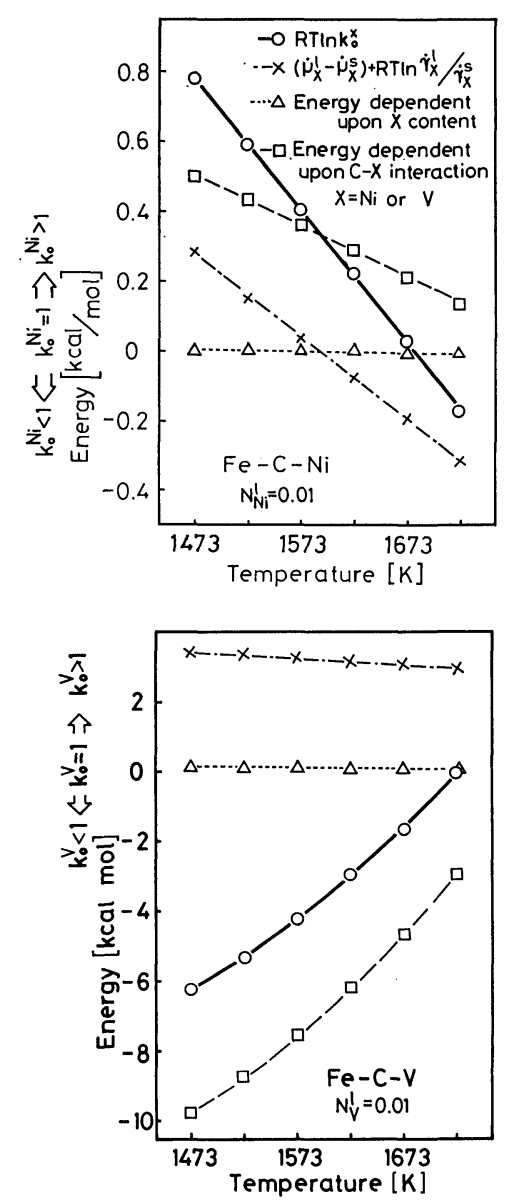

Fig. 13. Change of energy components concerning the distributions of $\mathrm{Ni}$ and $\mathrm{V}$ between solid and liquid with temperature.

liquid iron alloys seem to have fairly been established. However a comprehensive study for the solubilities of these elements in solid iron alloys has not yet been 
carried out.

In this section a simple equation of the equilibrium distribution coefficients of nitrogen and hydrogen between solid and liquid phases is derived thermodynamically and also the effects of various elements on the equilibrium distribution of nitrogen and hydrogen in iron base alloys are discussed.

Using Eqs. (1) to (3), the equilibrium distribution coefficient of element $i(i=\mathrm{N}$ or $\mathrm{H})$ in $\mathrm{Fe}-i-\mathrm{X}$ ternary system can be shown by

$$
\begin{aligned}
\ln k_{\circ}^{i}= & \left(\dot{\mu}_{i}^{l}-\dot{\mu}_{i}^{s}\right) / R T+\ln \left(\dot{\gamma}_{i}^{l} / \dot{\gamma}_{i}^{s}\right) \\
& +\left(\varepsilon_{i}^{i, l}-\varepsilon_{i}^{i, s} \cdot k_{\circ}^{i}\right) \mathcal{N}_{i}^{l}+\left(\varepsilon_{i}^{\mathrm{X}}, l-\varepsilon_{i}^{\mathrm{X}}, s \cdot k_{\circ}^{\mathrm{X}}\right) \mathcal{N}_{\mathbf{X}}^{l}
\end{aligned}
$$

Since it is well known that the dissolution of nitrogen or hydrogen in pure iron, either in the liquid state or in the solid one, obeys Sieverts' law, the selfinteraction parameters of nitrogen or hydrogen in iron are shown as

$$
\varepsilon_{i}^{i} \fallingdotseq 0
$$

As already mentioned, Mori and Ichise ${ }^{20)}$ proposed that a linear relation holds approximately between $\varepsilon_{\mathrm{N}}^{\mathrm{X}}, l$ of some elements $\mathrm{X}$ in liquid phase and $\varepsilon_{\mathrm{N}}^{\mathrm{X}}, s$ in austenite as shown in Fig. 14 and the gradient of this straight line becomes unity as the temperature of the liquid phase approaches that of solid one. So, the following equation can be assumed at the temperatures at which the liquid and the solid coexist.

$$
\varepsilon_{i}^{\mathrm{X}, l} \fallingdotseq \varepsilon_{i}^{\mathrm{X}, s}
$$

Substituting Eqs. (17) and (18) into Eq. (16) yields

$$
\begin{aligned}
\ln k_{\mathrm{o}}^{i}= & \left(\dot{\mu}_{i}^{l}-\dot{\mu}_{i}^{s}\right) / R T+\ln \left(\dot{\gamma}_{i}^{l} / \dot{\gamma}_{i}^{s}\right) \\
& +\left(1-k_{\circ}^{\mathrm{x}}\right) \cdot \varepsilon_{i}^{\mathrm{X}}, l \cdot \mathcal{N}_{\mathbf{X}}^{l} \quad \ldots . .
\end{aligned}
$$

The above equation describes that the equilibrium distribution coefficient consists of the terms

$$
\left(\dot{\mu}_{i}^{l}-\dot{\mu}_{i}^{s}\right) / R T+\ln \left(\dot{\gamma}_{i}^{l} / \dot{\gamma}_{i}^{s}\right)
$$

dependent on the property of nitrogen or hydrogen and the term

$$
\left(1-k_{\circ}^{\mathrm{x}}\right) \cdot \varepsilon_{i}^{\mathrm{x}}, l \cdot \mathcal{N}_{\mathbf{X}}^{l}
$$

showing the effect of the alloying element $\mathrm{X}$ on $k_{\mathrm{o}}^{i}$.

On the other hand, as the same way described in Eq. (16), the equilibrium distribution coefficient of the alloying element $\mathrm{X}, k_{\mathrm{o}}^{\mathrm{x}}$ is given by

$$
\begin{aligned}
\ln k_{\mathrm{o}}^{\mathrm{x}}= & \left(\dot{\mu}_{\mathrm{X}}^{l}-\dot{\mu}_{\mathrm{X}}^{s}\right) / R T+\ln \left(\dot{\gamma}_{\mathrm{X}}^{l} / \dot{\gamma}_{\mathrm{X}}^{s}\right) \\
& +\left(\varepsilon_{\mathrm{X}}^{\mathrm{x}}, l-\varepsilon_{\mathrm{X}}^{\mathrm{X}}, s \cdot k_{\mathrm{o}}^{\mathrm{x}}\right) \cdot \mathcal{N}_{\mathrm{X}}^{l} \\
& +\left(\varepsilon_{\mathrm{X}}^{i}, l-\varepsilon_{\mathrm{X}}^{i}, s \cdot k_{\mathrm{o}}^{i}\right) \cdot \mathcal{N}_{i}^{l} \ldots \ldots . .
\end{aligned}
$$

Here, the fourth term of the right-hand side of the above equation shows the effect of element $i$ on $k_{\circ}^{\mathrm{x}}$ but the $i$ is gaseous element and its solubility is quite small, then this term can be neglected. The third term of the right-hand side of Eq. (20) indicates the dependence of $k_{\circ}^{\mathrm{x}}$ on the concentration of $\mathrm{X}$. The contribution of this term to $k_{\circ}^{\mathrm{x}}$ is known to be much smaller than that of the first and second terms of the right-hand side of Eq. (20). So this term can be

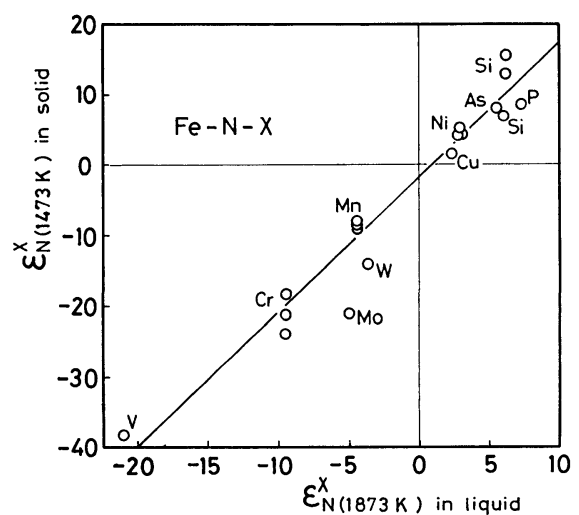

Fig. 14. Relation between $\varepsilon_{\mathrm{N}}^{\mathrm{X}}, l$ in liquid and $\varepsilon_{\mathrm{N}}^{\mathrm{X}}, s$ in austenite.

ignored, too. Thus, $k_{\circ}^{\mathrm{x}}$ depends on only the first and the second terms

$$
\left(\dot{\mu}_{\mathrm{x}}^{l}-\dot{\mu}_{\mathrm{x}}^{s}\right) / R T+\ln \left(\dot{\gamma}_{\mathrm{x}}^{l} / \dot{\gamma}_{\mathrm{x}}^{s}\right)
$$

and it can be considered to be constant at a given temperature.

Consequently, $k_{\circ}^{i}$ can be calculated by substituting the thermodynamic data into Eq. (19). Also, the effects of various alloying elements $\mathrm{X}$ on $k_{\circ}^{i}$ can be discussed.

It is obvious from Eq. (19) that the fundamental factor controlling $k_{\circ}^{i}$ s of nitrogen and hydrogen,

$$
\left(\dot{\mu}_{i}^{l}-\dot{\mu}_{i}^{s}\right) / R T+\ln \left(\dot{\gamma}_{i}^{l} / \dot{\gamma}_{i}^{s}\right)
$$

is equal to $k_{\mathrm{o}}^{i} \mathrm{~s}$ of these gaseous elements in $\mathrm{Fe}-\mathrm{N}$ and $\mathrm{Fe}-\mathrm{H}$ binary systems.

$$
\begin{aligned}
& \left(\dot{\mu}_{i}^{l}-\dot{\mu}_{i}^{s}\right) / R T+\ln \left(\dot{\gamma}_{i}^{l} / \dot{\gamma}_{i}^{s}\right) \\
& \quad=\ln k_{\circ}^{i}(\mathrm{Fe}-i \text { binary system })
\end{aligned}
$$

In order to obtain the fundamental factor controlling $k_{\mathrm{o}}^{i}$ in $\mathrm{Fe}-i-\mathrm{X}$ ternary system, $k_{\mathrm{o}}^{i} \mathrm{~s}$ of nitrogen and hydrogen in $\mathrm{Fe}-\mathrm{N}$ and $\mathrm{Fe}-\mathrm{H}$ binary systems will be estimated as follows. Figure 15 shows the temperature dependence of the solubilities of nitrogen and hydrogen in $\mathrm{Fe}-\mathrm{N}$ and $\mathrm{Fe}-\mathrm{H}$ binary systems. ${ }^{28}$ ) In this figure, extrapolating the solubility curves, we can obtain the solubilities of nitrogen and hydrogen in both the solid and the liquid phases at a given temperatures and subsequently $k_{\circ}^{i}$. Thus, the factor

$$
\left(\dot{\mu}_{i}^{l}-\dot{\mu}_{i}^{s}\right) / R T+\ln \left(\dot{\gamma}_{i}^{l} / \dot{\gamma}_{i}^{s}\right)
$$

can be estimated as shown in Table 4 .

Also, Eq. (19) indicates that the effects of various alloying elements $\mathrm{X}$ on $k_{\mathrm{o}}^{i}$ are calculated if the values of $k_{\circ}^{\mathrm{x}}$ and $\varepsilon_{i}^{\mathrm{x}}$ in the liquid are known. The calculated results of $\left(1-k_{\circ}^{\mathrm{x}}\right) \cdot \varepsilon_{i}^{\mathrm{x}}$ are listed in Table 5 together with the values of $k_{\circ}^{\mathrm{x}}{ }^{7)}$ and $\varepsilon_{i}^{\mathrm{x}} \mathbf{9 , 2 9 , 3 0 )}$ used in this calculation. Figures 16 and 17 show the change of the fourth term of Eq. (19) with $\mathcal{N}_{\mathrm{X}}^{l}$ in $\mathrm{Fe}-\mathrm{N}-\mathrm{X}$ and $\mathrm{Fe}-$ $\mathrm{H}-\mathrm{X}$ systems, respectively. These figures mean as follows. If

$$
\left(1-k_{\circ}^{\mathrm{x}}\right) \cdot \varepsilon_{i}^{\mathrm{x}}, l \cdot \mathcal{N}_{\mathbf{X}}^{l}
$$

is positive and becomes larger and larger, $k_{\circ}^{i}=\mathcal{N}_{i}^{s} / \mathcal{N}_{i}^{l}$ 

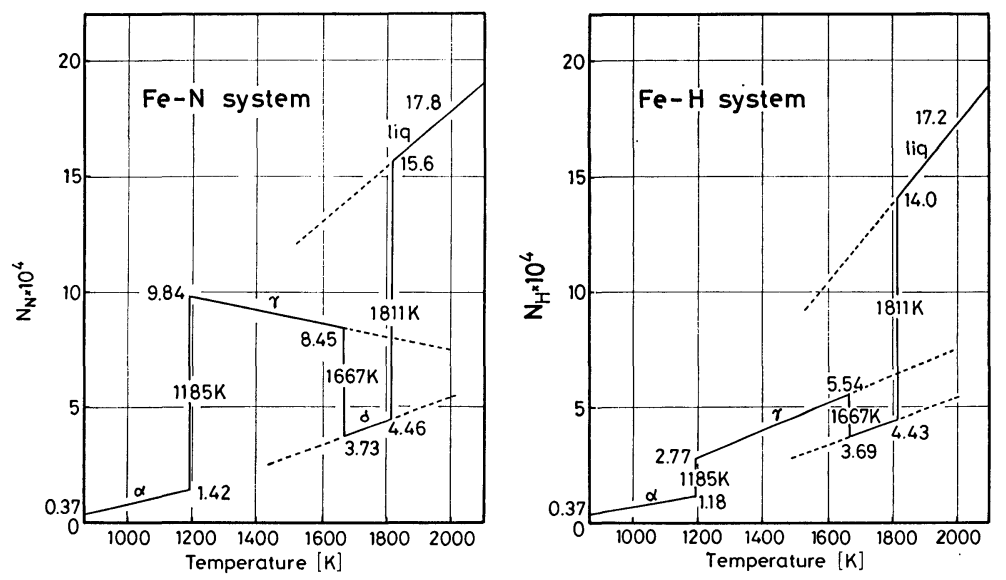

Fig. 15. Solubilities of nitrogen and hydrogen in iron.

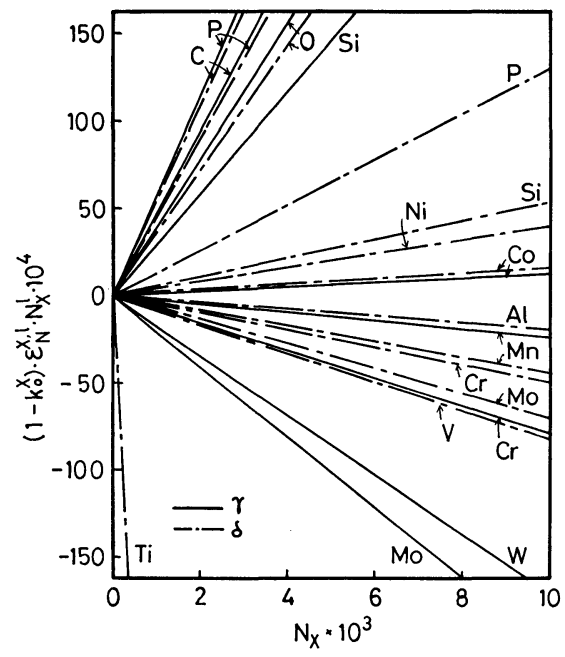

Fig. 16. Change of the effect of $\mathrm{X}$ on $k_{\mathrm{o}}^{\mathrm{N}}$ with concentration of $\mathrm{X}$ in $\mathrm{Fe}-\mathrm{N}-\mathrm{X}$ system.

Table 4. Equilibrium distribution coefficients of nitrogen and hydrogen.

\begin{tabular}{|c|c|c|c|c|c|c|c|}
\hline $\mathrm{Te}$ & ip. & $\mathcal{N}_{\mathrm{N}}$ & $0^{4}$ & $k^{N}$ & $\mathcal{N}_{\mathrm{H}}$ & & $k^{\mathrm{H}}$ \\
\hline & & & & & & & \\
\hline 1500 & 12 & 3.90 & 11. & 0.75 & $\gamma 4.60$ & 8.70 & 0.53 \\
\hline & & $\delta 2.90$ & & 0.24 & $\delta 2.80$ & & 0.32 \\
\hline 1600 & 1327 & $\gamma 8.60$ & 13.1 & 0.65 & $\gamma 5.20$ & 10.4 & 0.50 \\
\hline & & $\delta 3.4$ & & 0.26 & $\delta 3.35$ & & 0.32 \\
\hline 1700 & 1427 & $\gamma 8.30$ & 14.2 & 0.58 & $\gamma 5.75$ & 12.1 & 0.47 \\
\hline & & $\delta 3.90$ & & 0.27 & $\delta 3.80$ & & 0.31 \\
\hline 1800 & 1527 & $\gamma 8.00$ & 15.4 & 0.52 & $\gamma 6.30$ & 13.8 & 0.46 \\
\hline & & $\delta 4.40$ & & 0.28 & $\delta 4.30$ & & 0.31 \\
\hline
\end{tabular}

increases, that is to say, such an alloying element $\mathrm{X}$ lets nitrogen and hydrogen dissolve much more in the solid phase against a given solubility in the liquid phase, $\mathcal{N}_{i}^{l}$. On the other hand, if

$$
\left(1-k_{\circ}^{\mathrm{x}}\right) \cdot \varepsilon_{i}^{\mathrm{x}} \cdot \mathcal{N}_{\mathrm{X}}^{l}
$$

is negative and its absolute value becomes larger and larger, $k_{\circ}^{i}=\mathcal{N}_{i}^{s} / \mathcal{N}_{i}^{l}$ decreases and this element $\mathrm{X}$ impedes the dissolutions of these gaseous elements in the solid phase against a given $\mathcal{N}_{i}^{l}$.

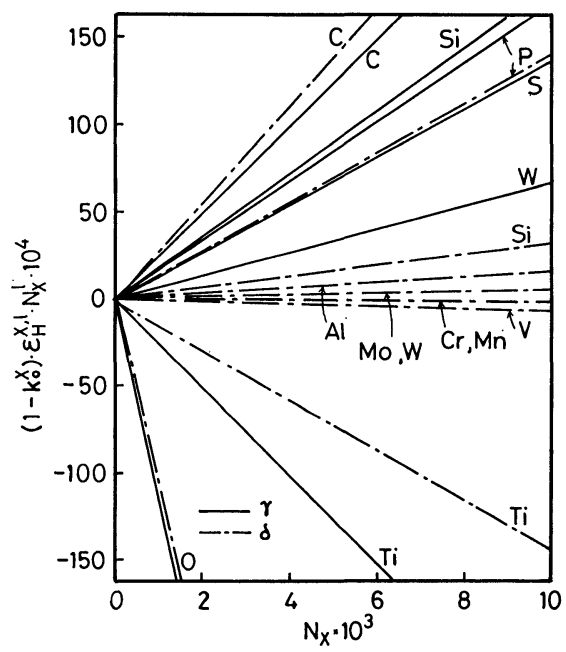

Fig. 17.

Change of the effect of $\mathrm{X}$ on $k_{\circ}^{\mathrm{H}}$ with concentration of $\mathrm{X}$ in $\mathrm{Fe}-\mathrm{H}-\mathrm{X}$ system.

Table 5. Data of $\varepsilon_{\mathrm{N}}^{\mathrm{x}}, \varepsilon_{\mathrm{H}}^{\mathrm{x}}, k_{\circ}^{\mathrm{x}}$ and calculated results of $\left(1-k_{\circ}^{\mathrm{x}}\right) \varepsilon_{i}^{\mathrm{X}}$.

\begin{tabular}{|c|c|c|c|c|c|c|}
\hline $\mathrm{x}$ & $\varepsilon_{\mathrm{N}}^{\mathrm{X}}$ & $\varepsilon_{\mathrm{H}}^{\mathrm{X}}$ & $k_{0}^{\mathrm{x}}$ & $1-k$ & $\left(1-k_{\mathrm{o}}^{\mathrm{X}}\right) \varepsilon_{\mathrm{N}}^{\mathrm{X}}$ & $\left(1-k_{\mathrm{o}}^{\mathrm{x}}\right) \varepsilon_{\mathrm{H}}^{\mathrm{X}}$ \\
\hline $\mathrm{Al}$ & -2.60 & 1.96 & $\delta 0.92$ & 0.08 & -0.208 & 0.157 \\
\hline \multirow{2}{*}{ G } & 7.22 & 3.76 & $\delta 0.25$ & 0.75 & 5.42 & 2.82 \\
\hline & & & $\gamma 0.35$ & 0.65 & 4.69 & 2.44 \\
\hline \multirow[t]{2}{*}{ Co } & 2.62 & 0.38 & $\delta 0.94$ & 0.06 & 0.157 & 0.0228 \\
\hline & & & $\gamma 0.95$ & 0.05 & 0.131 & 0.0190 \\
\hline \multirow[t]{2}{*}{$\mathrm{Cr}$} & -10.0 & -0.40 & $\delta 0.95$ & 0.05 & -0.501 & -0.0200 \\
\hline & & & $\gamma 0.87$ & 0.13 & -1.30 & -0.0520 \\
\hline \multirow[t]{2}{*}{$\mathrm{Mn}$} & -4.51 & -0.30 & $\delta 0.90$ & 0.10 & -0.451 & -0.0300 \\
\hline & & & $\gamma 0.95$ & 0.05 & -0.226 & -0.0150 \\
\hline \multirow[t]{2}{*}{ Mo } & -5.07 & 0.15 & $\delta 0.86$ & 0.14 & -0.710 & 0.0210 \\
\hline & & & $\gamma 0.60$ & 0.40 & -2.03 & 0.0600 \\
\hline \multirow[t]{2}{*}{$\mathrm{Ni}$} & 2.37 & 0.00 & $\delta 0.83$ & 0.17 & 0.403 & 0.00 \\
\hline & & & $\gamma 0.95$ & 0.05 & 0.119 & 0.00 \\
\hline \multirow[t]{2}{*}{$\mathrm{O}$} & 4.01 & -11.8 & $\delta 0.10$ & 0.90 & 3.61 & -10.6 \\
\hline & & & $\gamma 0.03$ & 0.97 & 3.89 & -11.5 \\
\hline \multirow[t]{2}{*}{$\mathrm{P}$} & 6.19 & 1.85 & $\delta 0.23$ & 0.77 & 4.77 & 1.42 \\
\hline & & & $\gamma 0.08$ & 0.92 & 5.69 & 1.70 \\
\hline \multirow[t]{2}{*}{$\mathrm{S}$} & 1.35 & 1.48 & $\delta 0.02$ & 0.98 & 1.32 & 1.45 \\
\hline & & & $\gamma 0.05$ & 0.95 & 1.28 & 1.41 \\
\hline \multirow[t]{2}{*}{$\mathrm{Si}$} & 5.94 & 3.62 & $\delta 0.91$ & 0.09 & 0.535 & 0.326 \\
\hline & & & $\gamma 0.50$ & 0.50 & 2.97 & 1.81 \\
\hline \multirow[t]{2}{*}{$\mathrm{Ti}$} & -105 & -3.61 & $\delta 0.60$ & 0.40 & -41.8 & -1.44 \\
\hline & & & $\gamma 0.30$ & 0.70 & -73.2 & -2.53 \\
\hline $\mathrm{V}$ & -19.5 & -1.47 & $\delta 0.96$ & 0.04 & -0.778 & -0.0588 \\
\hline \multirow[t]{2}{*}{ W } & -3.43 & 1.33 & $\delta 0.95$ & 0.05 & -0.172 & 0.0665 \\
\hline & & & $\gamma 0.50$ & 0.50 & -1.72 & 0.665 \\
\hline $\mathrm{Zr}$ & -238 & - & $\delta 0.50$ & 0.50 & -119 & - \\
\hline
\end{tabular}

\section{Summary}

In order to investigate nickel and vanadium distribution between the solid and the liquid phases in $\mathrm{Fe}-\mathrm{C}$ base ternary systems, austenite-liquid phases equilibrated in the temperature range from 1180 to $1420^{\circ} \mathrm{C}$ were quenched and the nickel and vanadium and carbon concentrations in each phase were analysed 
by an EPMA to obtain the equilibrium distribution of these solutes. Moreover, the factors which control the equilibrium distribution between solid and liquid phases in iron alloys were discussed thermodynamically. The results obtained are summarized as follows:

(1) The fundamental factors controlling the equilibrium distribution of solute element in iron alloys are the free energy of fusion of the solute element and the difference of the interchange energy of iron with the solute element between the solid and liquid phases.

(2) In iron base binary alloys the equilibrium distribution coefficient of the solute element changes periodically against the atomic number of the element.

(3) Particularly, in $\mathrm{Fe}-\mathrm{C}$ base ternary alloys the most important factor controlling the equilibrium distribution of the 3 rd element $\mathrm{X}$ is the interaction energy between $\mathrm{C}$ and $\mathrm{X}$.

(4) In Fe-C base ternary alloys, with the increasing carbon content the equilibrium distribution coefficient of the 3 rd element $\mathrm{X}, k_{\mathrm{o}}^{\mathrm{x}}$, increases for the repulsive interaction between $\mathrm{G}$ and $\mathrm{X}$ while $k_{\mathrm{o}}^{\mathrm{x}}$ decreases for the attractive one.

(5) The simple equation describing the equilibrium distribution coefficients of nitrogen and hydrogen, $k_{\circ}^{\mathrm{N}}$ and $k_{\circ}^{\mathrm{H}}$, were derived thermodynamically and the effects of the various elements on $k_{\circ}^{\mathrm{N}}$ and $k_{\circ}^{\mathrm{H}}$ were predicted.

Consequently, some distribution behaviours of solute elements between solid and liquid phases in iron base alloys could be discussed thermodynamically. Moreover, the above thermodynamic treatments are considered to be useful to investigate the propriety of the measured $k_{\circ}^{\mathrm{x}}$ and also to estimate $k_{\circ}^{\mathrm{x}}$ when there is no measured value in any alloy systems.

\section{REFERENCES}

1) S. Suzuki, T. Umeda and Y. Kimura: The 19th Comm. (Solidification), Japan Soc. Promotion Sci. (JSPS), Rep. No. 19-10254, (May, 1980).

2) A. Kagawa and T. Okamoto: Metal Sci., 14 (1980), 519.

3) A.J.W. Ogilvy, A. Ostrowskii and D. H. Kirkwood: Metal Sci., 15 (1981), 168.

4) A. Kagawa, K. Iwata and T. Okamoto: The Abstract for the 88th Lecture Meeting of Japan Institute of Metals, JIM, Sendai, (1981), 274.

5) T. Okamoto, Z. Morita, A. Kagawa and T. Tanaka: Tetsu-to-Hagané, 68 (1982), 244.

6) H. Wada and T. Saito: J. Japan Inst. Metals: 25 (1961), 159.
7) T. Takahashi, M. Kudo and K. Ichikawa: Solidification of Iron and Steel, A Data Book on the Solidification Phenomena of Iron and Steel, ed. by Solidification Comm., Joint Soc. Iron Steel Basic Research of ISIJ, ISIJ, Tokyo, (1977).

8) B. W. Mott: Phil. Mag., 2 (1957), 259.

9) G. K. Sigworth and J. F. Elliott: Metal Sci., 8 (1974), 298

10) E. J. Grinsey: J. Chem. Thermo., 9 (1979), 415.

11) T. Wada, H. Wada, J. F. Elliott and J. Chipman: Met. Trans., 2 (1971), 2199.

12) J. Chipman and J. F. Elliott: Trans. Met. Soc. AIME, 242 (1968), 35

13) T. Furukawa and E. Kato: Tetsu-to-Hagané, 61 (1975), 3050.

14) S. Ban-ya, J. F. Elliott and J. Ghipman: Met. Trans., 1 (1970), 1313.

15) J. Chipman: Met. Trans., 3 (1972), 55.

16) O. Kubaschewski and C. B. Alcock: Metallurgical Thermochemistry, 5th ed., Pergamon Press, New York, (1979), 336.

17) T. Nishizawa and M. Hasebe: Tetsu-to-Hagané, 67 (1981), 2086.

18) R. Hultgren, P. D. Desai, D. T. Hawkins, M. Gleiser and K. K. Kelley: Selected Values of the Thermodynamic Properties of Binary Alloys, ASM, Ohio, (1973).

19) T. Wada, H. Wada, J. F. Elliott and J. Chipman: Met. Trans., 3 (1972), 2865.

20) T. Mori and E. Ichise: J. Japan Inst. Metals, 32 (1968), 949.

21) K. Parameswaran, K. Metz and A. Morris: Met. Trans., 10A (1979), 1929

22) R. A. Buckley and W. Hume-Rothery: JISI, 197 (1964), 895.

23) B. A. Rickinson and D. H. Kirkwood: Met. Sci., 12 (1978), 138.

24) K. P. Vunin and U. N. Taran: On the Structure of Cast Iron, The New Japan Soc. Casting and Forging, Osaka, (1979).

25) A. Kagawa, S. Moriyama and T. Okamoto: J. Mat. Sci., 17 (1982), 135.

26) K. Suzuki, A. Taniguchi and K. Hirota: Tetsu-to-Hagané, 64 (1978), S606.

27) F. Neumann and H. Schenck：Arch. Eisenhüttenw., 30 (1959), 477.

28) Basic Open Hearth Steelmaking, ed. by Physical Chemistry of Steelmaking Comm., The Metallurgical Soc. of AIME, AIME, New York, (1964), 646.

29) Z. Morita, T. Tanaka and T. Yanai: The 19th Comm. (Reaction), Japan Soc. Promotion Sci. (JSPS), Rep. No. 19-10421, (Oct., 1982).

30) S. Ban-ya, F. Ishii and Y. Iguchi: The 19th Comm. (Reaction), Japan Soc. Promotion Sci. (JSPS), Rep. No. 19-10396, (Feb., 1982). 